Ning et al., Afr J Tradit Complement Altern Med. (2015) 12(3):75-84

http://dx.doi.org/10.4314/ajtcam.v12i3.9

CHINESE HERBAL MEDICINE AND PREDNISONE INCREASE PROPORTION OF SPLENIC $\mathrm{CD} 4^{+} \mathrm{CD} 25 \mathrm{FOXP}^{+}{ }^{+}$CELLS AND ALLEVIATE GLOMERULAR LESION IN MRL/LPR MICE

\author{
Lin Ning ${ }^{1^{*}}$, Zhong Jiaxi ${ }^{2}$, Liu Ye ${ }^{2}$, Feng Jieying ${ }^{3}$, Huang Ganghua ${ }^{4}$, Sun $\mathrm{Xia}^{5}$ \\ ${ }^{1}$ Traditional Chinese Medicine Dept. of Guangdong NO.2 Provincial People's Hospital. ${ }^{2}$ Department of Seasonal \\ Febrile Disease, Guangzhou University of Chinese Medicine. ${ }^{3}$ Dermatology and Venereology Dept. of Guangdong \\ NO.2 Provincial People's Hospital. ${ }^{4}$ Pediatrics Dept. of The First Affiliated Hospital of Guangzhou University of \\ Chinese Medicine. ${ }^{5}$ Comparative Medical Laboratory of Guangdong Medical Laboratory Animal Center. \\ "Corresponding author: Lin Ning, Email: linning1011@sina.com
}

\begin{abstract}
Objective: This study investigated the effects of Chinese herbal medicine and prednisone on $\mathrm{CD}^{+}{ }^{\mathrm{F}}$ oxP $3^{+} \mathrm{T}$ cells (Tregs) and Th17 cells in the MRL/lpr mouse model of systemic lupus erythematosus.

Methods: MRL/lpr mice were treated with herbal medicine (yin-nourishing and heat-clearing therapy), prednisone, and a combination of both for 7 weeks. The proportions of $\mathrm{CD}^{+} \mathrm{CD} 25^{+} \mathrm{FoxP} 3^{+}$cells, $\mathrm{CD} 4^{+} \mathrm{CD} 25^{-} \mathrm{FoxP} 3^{+}$cells, and $\mathrm{CD} 4^{+} \mathrm{IL}-17^{+}$cells in splenic mononuclear cell suspension were determined by flow cytometry. Histological slices of kidneys were stained by H\&E, PAS, and Masson's method. Activity indexes (AI) of glomerular lesions were scored.

Results: The result showed that both herbal medicine and prednisone significantly increased the proportion of $\mathrm{CD} 4^{+} \mathrm{CD} 25^{-} \mathrm{FoxP} 3^{+}$cells $(P<0.05)$, but lowered the proportion of $\mathrm{CD}^{+} \mathrm{CD} 25^{+} \mathrm{FoxP} 3^{+}$cells $(P<0.05)$ and $\mathrm{CD} 4^{+} \mathrm{IL}-17^{+}$cells $(P<0.05)$ in $\mathrm{MRL} / \mathrm{lpr}$ mice. Consequently, $\mathrm{CD}^{+} \mathrm{CD} 25^{-} \mathrm{FoxP}^{+}$cells became dominant $\mathrm{CD} 4^{+} \mathrm{FoxP}^{+}$cells after either treatment. AIl the glomerular lesions in both herbal medicine group and prednisone group were significantly lower than those in the model group $(P<0.05)$. AI was positively related with the proportion of $\mathrm{CD} 4{ }^{+} \mathrm{IL}-17^{+}$cells (Spearman's rho $\left.=0.4958, P<0.05\right)$, but was negatively correlated with the proportions of CD4 ${ }^{+}$Foxp $3^{+}$cells $(\mathrm{Spearman}$ 's rho $=$ -0.5934, $P<0.05)$ and $\mathrm{CD}^{+} \mathrm{CD} 25^{-}{ }^{-}{ }^{\circ}{ }^{2} P 3^{+}$cells (Spearman's rho $\left.=-0.5914, P<0.05\right)$.

Conclusion: Both Chinese herbal medicine and prednisone significantly enhanced the proportion of $\mathrm{CD} 4^{+} \mathrm{CD} 25^{-}$FoxP $3^{+}$cells and reduced the proportion of Th17 cells in lupus-prone MRL/lpr mice. Increased proportion of $\mathrm{CD}^{+} \mathrm{CD} 25^{-} \mathrm{FoxP}^{+}$cells was correlated with less severe glomerular lesions, indicating that $\mathrm{CD} 4^{+} \mathrm{CD} 25^{-} \mathrm{FoxP} 3^{+}$cells might play a regulatory role in the treatment of systemic lupus erythematosus.
\end{abstract}

Keywords: Systemic lupus erythematosus; regulatory T cells; Herbal medicine; Prednisone

\title{
Introduction
}

Systemic lupus erythematosus (SLE) is an autoimmune disease affecting almost all organs and tissues. Most cases of SLE are mild. However, in some severe cases, untreated lupus may progress from attack of skin and joints to internal organs including heart, lung, liver and kidney (with 
Ning et al., Afr J Tradit Complement Altern Med. (2015) 12(3):75-84

http://dx.doi.org/10.4314/ajtcam.v12i3.9

renal disease being the primary concern). Renal biopsies in patients with SLE display mesangial cell proliferation, inflammation, basement membrane abnormalities, and immune complex deposition under light and immunofluorescence microscopes (Mok, et al., 2003). In genetically predisposed animal models, environmental factors induce the breakdown of self-tolerance and trigger the outbreak of SLE (D'Cruz, et al., 2007, Tsokos, 2011). However, the pathogenic mechanisms of SLE have not yet been elucidated.

Although onset of SLE affects almost every part of the immune system, it is commonly believed that altered T lymphocytes homeostasis plays a pivotal role in the development of SLE. Regulatory T cells (Treg), a subpopulation of CD4+ lymphocytes characterized by expression of CD25 (IL-2R $\alpha$ ) or transcription factor FoxP3, participate in maintaining immune tolerance, and thus play a key role in suppressing the development of autoimmune diseases such as SLE (Buckner, 2010, Shevach, 2009). Studies have shown that SLE patients in the active phase of SLE are characterized by a deficiency in Treg cells and an expansion of Th17 cells, suggesting that the imbalance between Th17 cells and Treg cells might be responsible for the exacerbation of SLE (Kleczynska, et al., 2011, Yang, et al., 2009).

Therapies using immunosuppressive drugs such as corticosteroids and prednisone have been widely used in the treatment of SLE, and are proven to improve the overall survival and severe organ damage in SLE patients. Studies have discovered that corticosteroids treatment increases Treg cells and/or ratio of Treg cells to Th17 cells (Treg/Th17) in SLE patients (Azab, et al., 2008) (Ma, et al., 2010). However, there are currently few reports on the effects of prednisone therapy on Treg and Th17 cells.

In addition to immunosuppressive therapies, traditional Chinese medicine (TCM) has been increasingly applied in the treatment of SLE, among which the yin-nourishing and heat-clearing decoction is the most commonly used therapy (Hu, et al., 2002, LIANG Wei, 2005). From the perspective of TCM, SLE can be caused by different organic damage and in general divided into heat toxin syndrome and deficiency syndromes of Yin and Qi (Chen et al, 2011, Zhang et al, 1985). While the former typically has symptoms including fresh red skin rash, severe joint pain, multiple oral ulcers, high fever and dark colored urine (Xu et al, 2012), the latter is mainly characterized by benign skin rash, minor joint pain, lack of strength, shortness of breath, and small amount of urine ( $\mathrm{Li}$ and $\mathrm{Lu}, 2012$ ). Although formulas in treating SLE vary from each other, the therapeutic principle of these herbal medicines is based on their abilities to replenish Qi and Yin, remove internal heat, and clear the toxin (Zhao et al, 2012). In most cases, SLE is treated in China with corticosteroids, such as prednisone in adjunction with herbal therapies. Nevertheless, the effects of TCM on Th17 and Treg cells have not previously been studied.

In this study, lupus-prone MRL/lpr mice were treated with herbal medicine (nourishing-yin and clearing-heat therapy), prednisone or both in order to evaluate their efficacy in the treatment of SLE and to investigate whether the therapeutic effects of TCM and prednisone were mediated by their regulation on Treg cells and Th17 cells in MRL/lpr mice.

\section{Materials and Methods}

Animals

Female MRL/lpr mice (8 to 10 week old) were purchased from the Animal Research Center of Nanjing University. C57BL/6 mice of similar body weight and age were purchased from the Laboratory Animal Center of SUN Yat-sen University. The animal experiments were conducted according to the "Principles of Laboratory Animal Care" and with the approval of our ethics committee.

\section{Reagents}

Propylene glycol monomethyl ether acetate (PMA), ionomycin and monensin were purchased from Sigma (St. Louis, MO, USA). Antibodies were purchased from eBioscience (San Diego, CA, USA). Prednisone acetate tablets (Shanghai SINE Pharmaceutical, China) were dissolved 
Ning et al., Afr J Tradit Complement Altern Med. (2015) 12(3):75-84

http://dx.doi.org/10.4314/ajtcam.v12i3.9

into $0.5 \mathrm{mg} / \mathrm{mL}$. Chinese herbal prescription was a modified Qinghaobiejia decoction including $10 \mathrm{~g}$ of Artemisia apiacea, $30 \mathrm{~g}$ of Turtle shell, $20 \mathrm{~g}$ of Cornu bubali (decocted first), $10 \mathrm{~g}$ of Cortex Moutan, $20 \mathrm{~g}$ of Radix Rehmanniae, $10 \mathrm{~g}$ of Gentiana, and $10 \mathrm{~g}$ of Radix Scrophulariae, fourteen types of agents in total. The herbal medicine were provided by Chinese herbal pharmacy of Guangdong NO. 2 Provincial People's Hospital, decocted by traditional method, and concentrated into a solution of $1.1 \mathrm{~g}$ (content of crude drug) $/ \mathrm{mL}$.

\section{Treatment of animals}

The MRL/lpr mice were randomly divided into the following four groups with 8 mice in each group: model group, TCM group, prednisone group, and combination group. Another group of $8 \mathrm{C} 57 \mathrm{BL} / 6$ mice was used as control. Mice in the herbal medicine group were given concentrated TCM solution $(17.5 \mathrm{ml} / \mathrm{kg} / \mathrm{d})$. The prednisone group was given solution of prednisone acetate $(8.75 \mathrm{mg} / \mathrm{kg} / \mathrm{d})$. The combination group was given both herbal medicine and prednisone acetate of same dosage as the single-therapy groups. The model group and the control group were given normal saline of the equal volume. All the medicines and saline were administrated intragastrically. The treatment lasted seven weeks. The mice were executed on the $50^{\text {th }}$ day after treatment.

\section{Preparation of splenic mononuclear cells (SMCs)}

Spleens obtained from executed animals were immediately grounded. Mononuclear cells were isolated by filtration using a wire mesh strainer, collected by centrifugation, and resuspended in RPMI1640 culture medium at $3 \times 10^{9}$ cells $/ \mathrm{L}$.

\section{Identification of Treg and Th17 cells by flow cytometry}

In order to detect Treg cells, SMCs were stained with anti-mouse CD4 FITC, anti-mouse CD25 APC, and anti-mouse/rat FoxP3 PE according to the manufacturer's protocol, and analyzed by a FACSCalibur system (BD Biosciences, San Jose, CA, USA) on the same day of cell isolation.

In order to detect Th17 cells, SMCs were pre-incubated in $50 \mathrm{ng} / \mathrm{mL}$ PMA and $50 \mu \mathrm{g} / \mathrm{mL}$ ionomycin in a tissue culture incubator at $37^{\circ} \mathrm{C}$ for 1 $\mathrm{h}$, followed by incubation in $0.1 \mathrm{mg} / \mathrm{mL}$ monensin in a $5 \% \mathrm{CO} 2$ incubator at $37^{\circ} \mathrm{C}$ for $4 \mathrm{~h}$. Incubated cells were stained with anti-mouse/rat IL-17a PE and anti-mouse CD4 FITC, and analyzed by a FACSCalibur system.

\section{Pathological assessment of kidneys}

Perfusion-fixed tissue blocks from mouse kidneys were embedded in paraffin and sliced into $2 \mu \mathrm{m}$ sections. Slices were stained with H\&E, PAS and Masson's methods, respectively, and subjected to microscopic examination using Olympus BX41. Images were analyzed with an image analysis system (Image-Pro Express 5.1.1.14) in a blinded manner. Activity indexes (AI) of glomerular lesions were determined based on a previously reported method (Austin III, et al., 1983). Twenty glomeruli from each mouse were examined.

\section{Statistical analysis}

Statistical analysis was performed using Stata 11.0. Proportion of subpopulations was arcsine transformed. Differences among groups were analyzed by ANOVA and Scheffe tests (with homogeneous variance), or by Kruskal-Wallis and Nemenyi tests (with heterogeneous variance). 
Ning et al., Afr J Tradit Complement Altern Med. (2015) 12(3):75-84

http://dx.doi.org/10.4314/ajtcam.v12i3.9

Correlation between $\mathrm{AI}$ and proportion of $\mathrm{T}$ cell subpopulations was analyzed by Spearman rank correlation. $P$ value less than 0.05 was considered significant.

\section{Results}

\section{Proportions of Treg cell and Th17 cell}

The proportion of $\mathrm{CD}^{+} \mathrm{CD} 25^{+} \mathrm{FoxP} 3^{+}$or $\mathrm{CD} 4^{+} \mathrm{CD} 25^{-} \mathrm{FoxP}^{+}$cells in the model group was not significantly different from that in the control group $(P>0.05)$. The proportion of $\mathrm{CD} 4^{+} \mathrm{CD} 25^{+} \mathrm{FoxP} 3^{+}$cells in $\mathrm{TCM}$ and prednisone groups was significantly lower compared with the model group $(P<0.05)$, whereas the proportion of $\mathrm{CD}^{+} \mathrm{CD} 25^{-} \mathrm{FoxP} 3^{+}$cells in both groups was significantly higher $(P<0.05)$, indicating similar effects of both therapies on the proportion of Treg cells. However, the proportion of Treg cells in the combined therapy group was not significantly different from that in the model group $(P>0.05)$. The proportion of $\mathrm{CD} 4^{+} \mathrm{CD} 25^{-} \mathrm{FoxP} 3^{+}$cells in all 3 treatment groups was significantly higher than the proportion of $\mathrm{CD} 4^{+} \mathrm{CD} 25^{+} \mathrm{FoxP} 3^{+}$cells, resulting in $\mathrm{CD}^{+} \mathrm{CD} 25^{-} \mathrm{FoxP} 3^{+}$-dominant after the treatment (See Table 1 and Figure 1 ).

The proportion of $\mathrm{CD} 4^{+} \mathrm{IL}-17^{+}$cells in the model group was significantly higher than that in the control group $(P<0.05)$. The proportion of $\mathrm{CD} 4^{+} \mathrm{IL}-17^{+}$cells in all 3 treatment groups was significantly lower compared with the model group $(P<0.05)$.

Table 1: The proportion of three subpoplutions of T cells in different groups

\begin{tabular}{lcccc}
\hline Groups & $\mathrm{CD} 25^{+} \mathrm{FoxP}^{+} /$ & $\mathrm{CD} 25^{-} \mathrm{FoxP}^{+} / \mathrm{CD} 4$ & $\mathrm{IL}-17^{+} / \mathrm{CD}^{+}$ & $\mathrm{IL}^{+} 17^{+} / \mathrm{FoxP}^{+}$ \\
& $\mathrm{CD}^{+}(\%)$ & $(\%)$ & $(\%)$ & $(\%)$ \\
Control group & $(2.65 \pm 0.08)$ & $(3.78 \pm 0.74)$ & $(4.55 \pm 0.28)^{*}$ & $72 \pm 12.62$ \\
Model group & $(4.38 \pm 0.27)$ & $(1.73 \pm 0.48)$ & $(5.6 \pm 0.18)$ & $92.91 \pm 12.84$ \\
Herbal medicine group & $(1.62 \pm 0.22)^{*}$ & $(12.43 \pm 0.59)^{*}$ & $(4.51 \pm 0.22)^{* \#}$ & $32.16 \pm 1.28^{*} \# \oplus$ \\
Prednisone group & $(1.54 \pm 0.08)^{*}$ & $(10.05 \pm 0.16)^{*}$ & $(4.96 \pm 0.12)^{*}$ & $42.78 \pm 1.06^{*}$ \\
Combination group & $(2.51 \pm 0.21)$ & $(5.46 \pm 0.32)$ & $(4.72 \pm 0.12)^{*}$ & $59.27 \pm 2.92^{*}$ \\
\hline
\end{tabular}

Original ratio of subpopulation was arcsine-square-root transformed.

*, $P<0.05$ when compared with the model group; \#, $P<0.05$ when compared with prednisone group; and $\oplus, P<0.05$ when compared with the combination group.

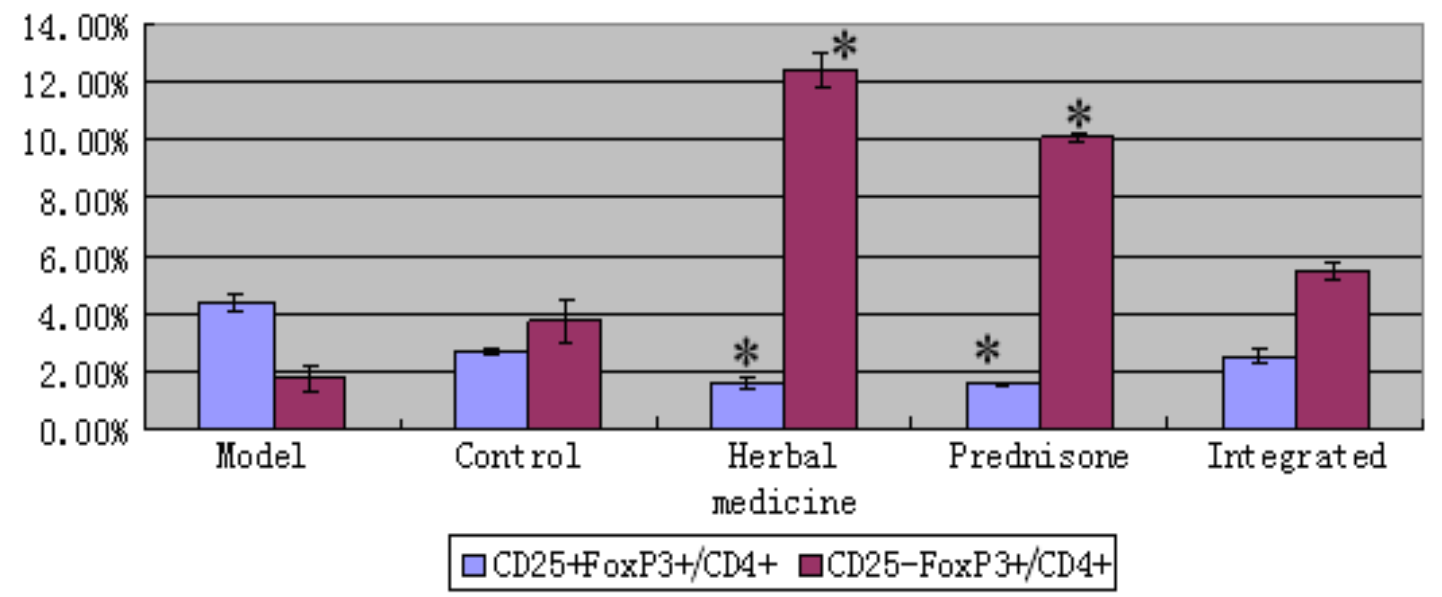

Figure1: The proportions of $\mathrm{CD} 25^{+} \mathrm{FoxP} 3^{+} / \mathrm{CD} 4^{+}$and $\mathrm{CD} 25^{-} \mathrm{FoxP} 3^{+} / \mathrm{CD} 4^{+}$in different groups

*, indicates $P<0.05$ when compared with the model group. 
Ning et al., Afr J Tradit Complement Altern Med. (2015) 12(3):75-84

http://dx.doi.org/10.4314/ajtcam.v12i3.9

\section{AI of glomerular lesions}

As shown in Figure 2, the glomerular lesions in MRL/lpr mice in all three treatment groups were significantly ameliorated compared with the model group as demonstrated by pathological assessment of kidneys by H\&E, PAS and Masson's staining. Furthermore, AIs of glomerular lesions in all three treatment groups were significantly lower than that in the model group $(P<0.05)$ (See Table2).

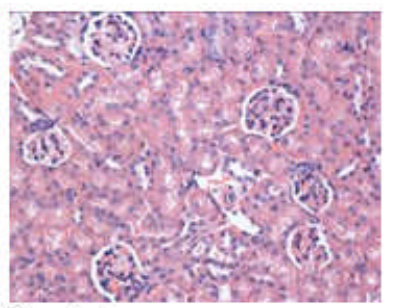

Control group: a

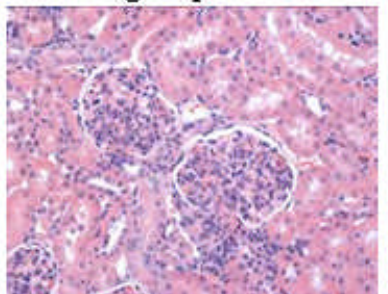

Model group: a

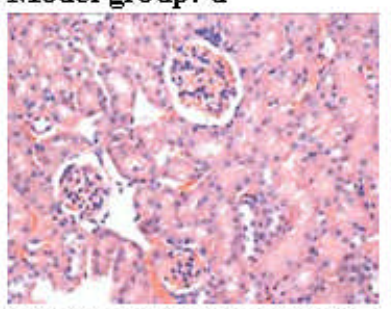

Herbal medicine group: a

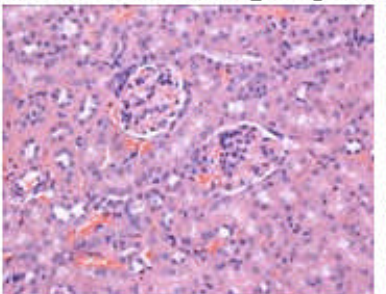

Prednisone group: a

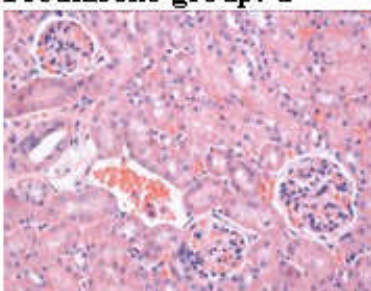

Combined therapy group: a

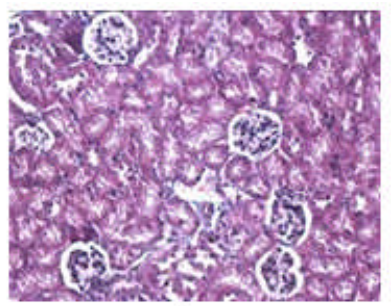

b

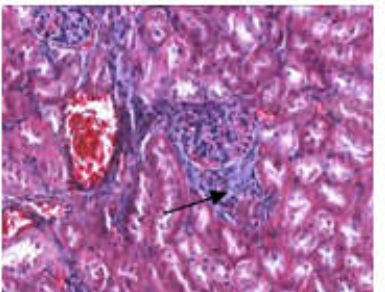

b

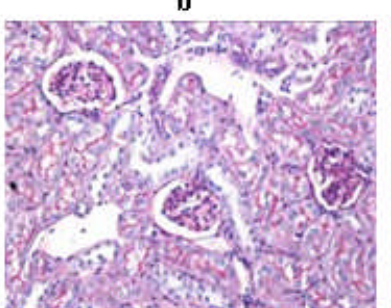

b

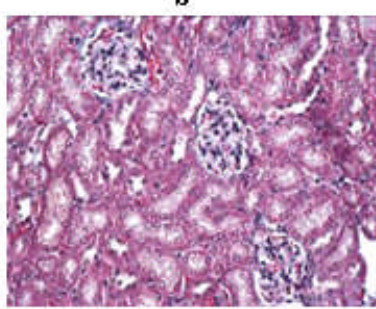

b

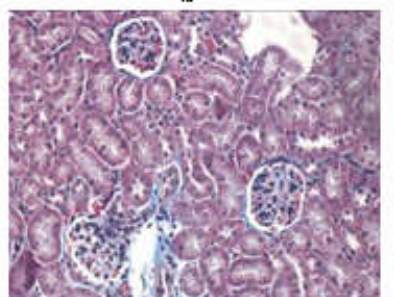

b

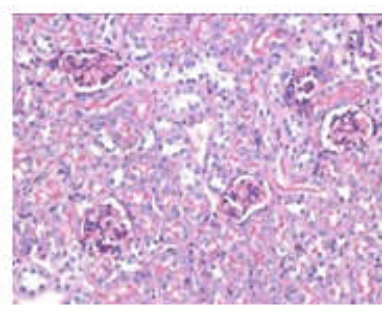

c

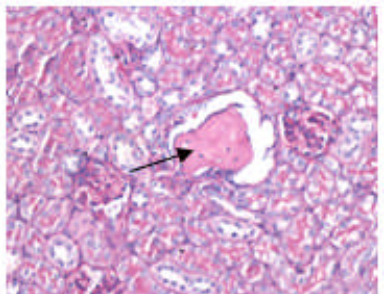

c

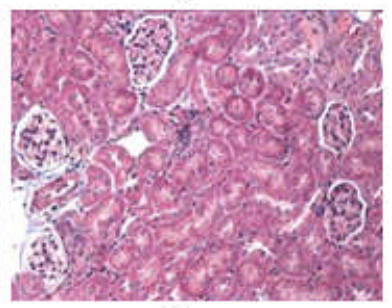

c

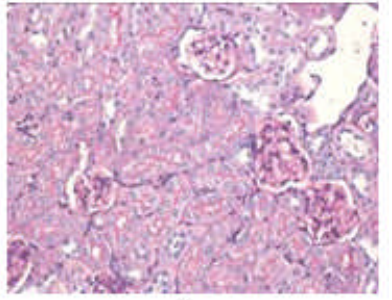

c

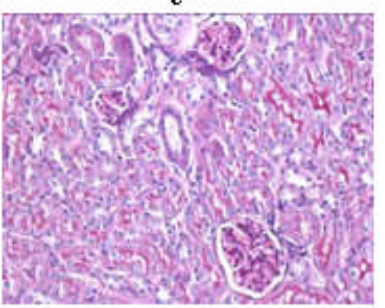

c

Figure 2: Pathological analysis of glomerular lesions in all groups by H\&E, PAS and Masson's staining. a, H\&E staining (X400), b, Masson staining (X400), and c, PAS staining (X400). Glomerular lesions are marked by black arrows. 
Ning et al., Afr J Tradit Complement Altern Med. (2015) 12(3):75-84

http://dx.doi.org/10.4314/ajtcam.v12i3.9

Table 2: AIs of glomerular lesions in different groups

\begin{tabular}{ll}
\hline & AI of glomerular lesions \\
\hline Model group & $9.75 \pm 1.49$ \\
Herbal medicine group & $3.50 \pm 0.53^{*}$ \\
Prednisone group & $3.38 \pm 1.19^{*}$ \\
Combination group & $4.00 \pm 1.41^{*}$ \\
\hline
\end{tabular}

Notes: $* P<0.05$, compared with Model group

\section{Correlation between $\mathrm{AI}$ of glomerular lesions and the proportion of $\mathrm{T}$ cell subpopulations}

Results of Spearman rank correlation (Table 3) showed that the ratio of CD25-FoxP3 ${ }^{+} / \mathrm{CD}^{+}{ }^{+}$cells (Spearman's rho=-0.5914, $P<0.05$ ) and $\mathrm{CD}^{+}{ }^{+}$FoxP $3^{+}$cells (Spearman's rho $\left.=-0.5934, P<0.05\right)$ were negatively correlated with AIs of glomerular lesions, whereas the ratio of Th17 cells was positively correlated with AIs in MRL/lpr mice (Spearman's rho=-0.4958, $P<0.05$ ).

Table 3:. Correlation between the ratio of $\mathrm{T}$ cell subpopoulations and AI of glomerular lesions

\begin{tabular}{|c|c|c|c|c|}
\hline \multirow[t]{2}{*}{ Ratio of subpopulation } & \multicolumn{3}{|c|}{ No. of mouse with different AI levels } & \multirow{2}{*}{$\begin{array}{l}\text { Total } \\
\text { number }\end{array}$} \\
\hline & $0-4$ & $5-8$ & $9-12$ & \\
\hline \multicolumn{5}{|l|}{$\mathrm{CD}^{+} \mathrm{FoxP}^{+\mathrm{a}}$} \\
\hline $4.80 \%-7.80 \%$ & 0 & 4 & 6 & 10 \\
\hline $7.81 \%-11.69 \%$ & 10 & 1 & 0 & 11 \\
\hline $11.70 \%-15.0 \%$ & 10 & 1 & 0 & 11 \\
\hline \multicolumn{5}{|l|}{$\mathrm{CD}^{+} \mathrm{CD} 25^{-} \mathrm{FoxP}^{+\mathrm{b}}$} \\
\hline $0 \%-5.00 \%$ & 0 & 3 & 6 & 9 \\
\hline $5.01 \%-10.00 \%$ & 9 & 2 & 0 & 11 \\
\hline $10.01 \%-13.22 \%$ & 11 & 1 & 0 & 12 \\
\hline \multicolumn{5}{|l|}{$\operatorname{Th} 17^{\mathrm{c}}$} \\
\hline $4.10 \%-4.70 \%$ & 8 & 2 & 0 & 10 \\
\hline $4.71 \%-5.10 \%$ & 11 & 2 & 0 & 13 \\
\hline $5.11 \%-5.91 \%$ & 1 & 2 & 6 & 9 \\
\hline
\end{tabular}

a: Spearman's rho $=-0.5934, P=0.0002$

b: Spearman's rho $=-0.5914, P=0.0002$

c: Spearman's rho $=0.4958, P=0.0029$ 


\section{Discussion}

In this study, we found that the glomerular lesions in MRL/lpr mice in all three treatment groups were significantly ameliorated compared with the model group as revealed by the histological study of the kidneys. Furthermore, AIs of glomerular lesions in all three treatment groups were significantly lower than that in the model group, suggesting that both the yin-nourishing and heat-clearing therapy, and prednisone were effective in the treatment of SLE. These results were consistent with previous literature which suggested that Chinese herbs alone could function reasonably well as a treatment for lupus (Fan et al. 1999, Wen 2001). However, we also found that there was no significantly difference in AIs of glomerular lesions between the combined group and the herbal medicine or prednisone group, suggesting that the combined therapy was not superior to either therapy. The results were contrary to previous findings that Chinese medicine appears to be suitable as an adjunct to modern medical therapies (Wu et al, 1998, Zhong et al, 1999) and herbal medicine has substantially reduced the dosage of corticosteroids needed for an effective treatment in SLE patients (Zhong et al., 2013). The inconsistence might be caused by different response to the combination therapy in MRL/lpr lupus mice. Furthermore, the combination therapy might offer potential clinical advantages such as the improvement of the overall physical condition and long-term quality of life of SLE patients even although it could not significantly change one or more laboratory indicators of the disease.

In studies of SLE related immune disorders, it has been confirmed that $\mathrm{CD} 4^{+} \mathrm{CD} 25^{+} \mathrm{FoxP} 3^{+}$cells (Tregs) suppress humoral autoimmunity primarily by direct inhibition of autoreactive B cells (Iikuni, et al., 2009). Intervention such as corticosteroids treatment increases the proportion of Treg cells or the Treg/Th17 ratio in SLE patients (Ma, et al., 2010). As the key player of peripheral immune tolerance, Tregs frequently indicate impaired functions in SLE patients (Xing, et al., 2012a), accompanied by an increase of Th17 (Xing, et al., 2012b). The $\mathrm{CD}^{+} \mathrm{CD} 25^{-} \mathrm{FoxP}^{+}$subpopulation have been recently found to be associated with the progression of SLE. The number of these cells increases in new-onset SLE patients. $\mathrm{CD}^{+} \mathrm{CD} 25^{-} \mathrm{FoxP}^{+}$is a potential precursor of functional Tregs. Studies concerning characteristics of subpopulation of Tregs indicated that expression of Foxp3 converts naïve $\mathrm{CD}^{+} \mathrm{CD}^{-} 5^{-} \mathrm{T}$ cells to phenotypical and functional Treg cells (Hori, et al., 2003). This is supported by a study of Bing Yan et.al, which suggests that $\mathrm{CD} 4{ }^{+} \mathrm{CD} 25^{-} \mathrm{FoxP}^{+}$is potential reservoir of $\mathrm{CD} 4{ }^{+} \mathrm{CD} 25^{+} \mathrm{FoxP}^{+}$cells $(\mathrm{Yan}$, et al., 2009). Furthermore, it is reported that most $\mathrm{CD} 4^{+} \mathrm{CD} 25^{-} \mathrm{FoxP}^{+}$cells in SLE patients expression memory $\mathrm{CD} 4^{+} \mathrm{T}$ cells marker, $\mathrm{CD} 45 \mathrm{RO}$, indicating that $\mathrm{CD}^{+} \mathrm{CD} 25^{-} \mathrm{FoxP}^{+}$cells may be the origin of adaptive $\mathrm{CD} 4^{+} \mathrm{CD} 25^{+} \mathrm{FoxP}^{+}$cells(Walker, et al., 2005). Some scientists believe that the increase of $\mathrm{CD} 4^{+} \mathrm{CD} 25^{-} \mathrm{FoxP} 3^{+}$cells serves as compensation for loss of $\mathrm{CD} 4^{+} \mathrm{CD} 25^{+} \mathrm{FoxP} 3^{+}$cells (Suen, et al., 2012). On the other hand, blocking of CD25 with Basiliximab, an anti-CD25 monoclonal antibody, did not change the proportion of FoxP3+ cells among CD4 T cells (de Herve, et al., 2010). Obviously, the alteration in T cell subpopulations remains controversy. Moreover, the clinical significance of their alteration in SLE patients is largely unclarified. In this study, we found that the percentages of $\mathrm{CD} 4^{+} \mathrm{CD} 25^{+} \mathrm{FoxP} 3^{+}$cells (Treg cells) in the model group were higher than that in the control group, and were down-regulated by herbal medicine or prednisone therapy. Furthermore, a slightly decreased proportion of $\mathrm{CD}^{+} \mathrm{CD} 25^{-} \mathrm{FoxP}^{+}$cells was observed in the model group compared with the control group, and was substantially up-regulated after either treatment. Consequently, CD4+CD25-FoxP3+ cells became dominant CD4+ FoxP3+ cells after either treatment. We also found that the percentage of Th17 cells in the model group was higher compared with the control group, and was significantly reduced by either intervention. Based on the aforementioned evidences, we proposed that $\mathrm{CD} 4^{+} \mathrm{CD} 25^{-} \mathrm{FoxP}^{+}$to some extent exerted similar suppressive effect on SLE as that reported in other studies described above, and the increase in the proportion of $\mathrm{CD} 4^{+} \mathrm{CD} 25^{-}$FoxP $3^{+}$after intervention is either a potential prelude of functional SLE suppressor Tregs, or a subset of functional Tregs itself.

Our study has several limitations. First, it examined only one dosage of herbal medicine, whereas three dosages (low, moderate and high dosages) are generally included in other studies (Zhong et al., 2013). Future comprehensive studies will be needed including different dosages of herbal medicine as well as dosages of both herbal medicine and prednisone. Second, our study revealed the therapeutic effect of both the herbal 
Ning et al., Afr J Tradit Complement Altern Med. (2015) 12(3):75-84

http://dx.doi.org/10.4314/ajtcam.v12i3.9

medicine and prednisone, but did not compare the side effects of them. Prednisone has been previously found to cause a variety of side effects, such as musculoskeletal complications like avascular necrosis and Cushinoid symptoms (Petri, 1995), whereas Chinese herbal medicine has been considered to be a more safe and effective treatment compared to prednisone (Zhong et al., 2013).

In summary, the herbal medicine (nourishing-yin and clearing-heat therapy) and prednisone alone or in combination were effective in the treatment of SLE by significantly ameliorating glomerular lesions in SLE mice. We also found that both Chinese herbal medicine (nourishing-yin and clearing-heat therapy) and prednisone could effectively enhance the proportion of $\mathrm{CD} 4^{+} \mathrm{CD} 25^{-} \mathrm{FoxP} 3^{+}$cells and reduce the proportion of Th17 cells in lupus-prone MRL/lpr mice. AI of glomerular lesions was positively correlated with the proportion of Th17 cells, but negatively correlated with the proportion of $\mathrm{CD}^{+} \mathrm{CD}^{2} 5^{-} \mathrm{FoxP}^{+}$cells. Neither herbal medicine nor prednisone promoted proliferation of $\mathrm{CD} 4^{+} \mathrm{CD} 25^{+} \mathrm{FoxP}^{+}$cells in these mice. We suspected that $\mathrm{CD} 4^{+} \mathrm{CD} 25^{-} \mathrm{FoxP}^{+}$cells are potential precursors of functional $\mathrm{CD} 4^{+} \mathrm{CD} 25^{+} \mathrm{FoxP} 3^{+}$ cells. However, dynamic simultaneous sampling of SMCs and peripheral blood mononuclear cells (PBMC) will be needed to validate our suspicion. It is also worth noting that the combined therapy was not as effective as individual therapies. The underlying mechanism requires further studies.

\section{Acknowledgment}

This work was sponsored by Guangdong Provincial Administration of Traditional Chinese Medicine (20121265).

\section{Conflict of interest: None.}

\section{References}

1. Austin III, H. A., Muenz, L. R., Joyce, K. M., Antonovych, T. A., Kullick, M. E., Klippel, J. H., Decker, J. L. and Balow, J. E. (1983). Prognostic factors in lupus nephritis: contribution of renal histologic data. The American journal of medicine. 75: 382-391

2. Azab, N., Bassyouni, I., Emad, Y., Abd El-Wahab, G., Hamdy, G. and Mashahit, M. (2008). CD4+ CD25+ regulatory T cells (TREG) in Systemic Lupus Erythematosus (SLE) patients: The possible influence of treatment with corticosteroids. Clinical Immunology. 127: 151-157

3. Buckner, J. H. (2010). Mechanisms of impaired regulation by CD4+ CD25+ FOXP3+ regulatory T cells in human autoimmune diseases. Nature Reviews Immunology. 10: 849-859

4. D'Cruz, D. P., Khamashta, M. A. and Hughes, G. R. (2007). Systemic lupus erythematosus. Lancet. 369: 587-96

5. Chen DP, Wong CK, Leung PC, Fung KP, Lau CB, Lau CP, Li EK, Tam LS, Lam CW. (2011). Anti-inflammatory activities of Chinese herbal medicine sinomenine and Liang Miao San on tumor necrosis factor-a-activated human fibroblastlike synoviocytes in rheumatoid arthritis. Journal of Ethno pharmacologyvol. 137: 457-468.

6. de Herve, M.-G. d. G., Gonzales, E., Hendel-Chavez, H., Décline, J.-L., Mourier, O., Abbed, K., Jacquemin, E. and Taoufik, Y. (2010). CD25 appears non essential for human peripheral Treg maintenance in vivo. PloS one. 5: e11784

7. Fan YS, Wen CP, Li XM, Tang XP, Li H, Li YW (1999). Observation on clinical effect of hormone combined with toxin-cleaning, stasis-resolving, and yin-nourishing method for the treatment of systemic lupus erythematosus. Chinese Journal of Integrated Traditional Chinese Medicine and Western Medicine. 19: 626-627.

8. Hori, S., Nomura, T. and Sakaguchi, S. (2003). Control of regulatory T cell development by the transcription factor Foxp3. Science. 299: 1057-1061 
Ning et al., Afr J Tradit Complement Altern Med. (2015) 12(3):75-84

http://dx.doi.org/10.4314/ajtcam.v12i3.9

9. Hu, D. and Li, M. (2002). Effects of Chinese Drugs for Nourishing Yin and Clearing the Heat on Sex Hormone Regulation and Clinical Efficacy in Systemic Lupus Erythematosus. Chinese Journal of Dermatology. 35: 389-392

10. Iikuni, N., Lourenço, E. V., Hahn, B. H. and La Cava, A. (2009). Cutting edge: regulatory T cells directly suppress B cells in systemic lupus erythematosus. The Journal of Immunology. 183: 1518-1522

11. Kleczynska, W., Jakiela, B., Plutecka, H., Milewski, M., Sanak, M. and Musial, J. (2011). Imbalance between Th17 and regulatory T-cells in systemic lupus erythematosus. Folia Histochemica et Cytobiologica. 49: 646-653.

12. Li HH and Lu XL. (2012). An overview of Chinese medicine in the treatment of systemic lupus erythematosus. Modern Journal of Integrated Traditional Chinese and Western Medicineno. 21: 4100-4102.

13. LIANG Wei, Z. L.-1., LU Yan. (2005). Effect of Method of Clearing Heat, Removing Blood Stasis and Nourishing Yin on bcl-2mRNA Expression of Peripheral Lymphocyte of Patients with Systemic lupus Erythematosus. Journal of Nanjing University of Traditional Chinese Medicine. 21: 157-158

14. Liu, M. F., Wang, C. R., Fung, L. L. and Wu, C. R. (2004). Decreased CD4+ CD25+ T cells in peripheral blood of patients with systemic lupus erythematosus. Scandinavian journal of immunology. 59: 198-202

15. Ma, J., Yu, J., Tao, X., Cai, L., Wang, J. and Zheng, S. G. (2010). The imbalance between regulatory and IL-17-secreting CD4+ T cells in lupus patients. Clin Rheumatol. 29: 1251-1258

16. Mok, C. and Lau, C. (2003). Pathogenesis of systemic lupus erythematosus. Journal of clinical pathology. 56: 481-490

17. Petri M. (1995). Musculoskeletal complications of systemic lupus erythematosus in the Hopkins Lupus Cohort: an update. Arthritis Care Res 8: $137-145$

18. Shevach, E. M. (2009). Mechanisms of Foxp3+ T Regulatory Cell-Mediated Suppression. Immunity. 30: 636-645

19. Suen, J.-L. and Chiang, B.-L. (2012). CD4+ FoxP3+ regulatory T-cells in human systemic lupus erythematosus. Journal of the Formosan Medical Association. 111: 465-470

20. Tsokos, G. C. (2011). Systemic lupus erythematosus. N Engl J Med. 365: 2110-21

21. Valencia, X., Yarboro, C., Illei, G. and Lipsky, P. E. (2007). Deficient CD4+ CD25high T regulatory cell function in patients with active systemic lupus erythematosus. The Journal of Immunology. 178: 2579-2588

22. Walker, M. R., Carson, B. D., Nepom, G. T., Ziegler, S. F. and Buckner, J. H. (2005). De novo generation of antigen-specific CD4+ CD25+ regulatory T cells from human CD4+ CD25-cells. Proc Natl Acad Sci U S A. 102: 4103-4108

23. Wen CP, Fan YS, Li XM (2001). Effect of Langchuangding on serum soluble interleukin-2 receptor and neopterin level in patients of systemic lupus erythematosus. Chinese Journal of Integrated Traditional Chinese Medicine and Western Medicine. 21: 339-341.

24. Wu X, et al. (1998). Clinical observation on nephrotic syndrome of lupus nephritis treated with integrated Chinese and Western medicine. Chinese Journal of Integrated Traditional Chinese Medicine and Western Medicine. 18: 718-720.

25. Xu XF, Qu HR, Xiang ZY, Mao JC, Zhao BJ, Wang X, Su L (2012). Effects of Ziyin Jiedu Quyu Decoction on gluco corticoid dosage in systemic lupus erythematosus: a double-blind randomized controlled trial. Shanghai Journal of Traditional Chinese Medicine. 46: 33-36.

26. Xing, Q., Wang, B., Su, H., Cui, J. and Li, J. (2012). Elevated Th17 cells are accompanied by FoxP3+ Treg cells decrease in patients with lupus nephritis. Rheumatol Int. 32: 949-958

27. Yan, B. and Liu, Y. (2009). The Nature of Increased Circulating CD4+ CD25-Foxp3+ T Cells in Patients with Systemic Lupus Erythematosus: A Novel Hypothesis. Open Rheumatology Journal. 3:22-24.

28. Yang, J., Chu, Y., Yang, X., Gao, D., Zhu, L., Yang, X., Wan, L. and Li, M. (2009). Th17 and natural Treg cell population dynamics in systemic lupus erythematosus. Arthritis \& Rheumatism. 60: 1472-1483

29. Zhang BY, Dong JH, and Zhou ZY. (1985). Traditional Chinese internal medicine. Shanghai Science and Technology Press, 1985. 
Ning et al., Afr J Tradit Complement Altern Med. (2015) 12(3):75-84

http://dx.doi.org/10.4314/ajtcam.v12i3.9

30. Zhang, B., Zhang, X., Tang, F., Zhu, L., Liu, Y. and Lipsky, P. (2008). Clinical significance of increased CD4+ CD25- Foxp3+ T cells in patients with new-onset systemic lupus erythematosus. Annals of the rheumatic diseases. 67: 1037-1040

31. Zhao BJ, Mao JC, Chen XJ, Su L, Gu JH (2012). Efficacy observation on mild to moderate active systemic lupus erythematosus treated with compound Zishenqing formula. World Journal of Integrated Traditional and Western Medicine. 7: 37-39.

32. Zhong JX, Peng SQ, Zhang JY, Liang LQ (1999). 25 cases of systemic lupus erythematosus treated by integrated traditional Chinese medicine and Western medicine. Chinese Journal of Integrated Traditional Chinese Medicine and Western Medicine. 19: 47-48.

33. Zhong LD, Bian ZX, Gu JH, Zhou X, Tian Y, Mao JC and Chen XJ. (2013). Chinese herbal medicine (Zi Shen Qing) for mild-to-moderate systematic lupus erythematosus: a pilot prospective, single-blinded, randomized controlled study. Evidence-based Complementary and Alternative Medicine. 2013: $1-10$. 